\title{
The Effect of Co and Zn Addition on Densification and Electrical Properties of Ceria-Based Nanopowders
}

\author{
Lúcia Adriana Villas-Boas ${ }^{a *}$, Pedro Augusto de Paula Nascente ${ }^{a}$, Richard Landers ${ }^{b}$, Marcelo Campos ${ }^{c}$, \\ Dulcina Maria Pinatti Ferreira de Souza ${ }^{a}$ \\ ${ }^{a}$ Department of Materials Engineering, Federal University of São Carlos - UFSCAR, São Carlos, SP, Brazil \\ ${ }^{b}$ Department of Applied Physics, Campinas, Institute of Physics, State University of Campinas - \\ UNICAMP, Campinas, SP, Brazil \\ ${ }^{c}$ Department of Biosystems Engineering, São Paulo State University - UNESP, Tupã Campus, Tupã, SP, Brazil
}

Received: October 21, 2015; Revised: May 26, 2016; Accepted: July 25, 2016

\begin{abstract}
In this work, cobalt and zinc-doped $\mathrm{Ce}_{0.8} \mathrm{Gd}_{0.2} \mathrm{O}_{1.9}$ samples were prepared starting from a commercial nanopowder and compared to the undoped material. The powder samples were pressed and afterwards sintered by a two-step procedure, before characterization by X-Ray Diffraction (XRD), X-ray photoelectron spectroscopy (XPS), Scanning Electron Microscopy (SEM), Transmission Electron Microscopy (TEM) and Impedance Spectroscopy (IS) in air. Cobalt or zinc additions are effective as sintering aid, allowing peak sintering temperatures around $1000^{\circ} \mathrm{C}$ to reach densifications above of $93 \%$ of theoretical density, showing no evidence for the presence of secondary phases. The total conductivity at $800^{\circ} \mathrm{C}$ of pressed $\mathrm{Zn}$-doped samples $\left(6.7 \times 10^{-2} \mathrm{~S} / \mathrm{cm}\right)$ and Co-doped samples $\left(7.5 \times 10^{-2}\right.$ $\mathrm{S} / \mathrm{cm})$ is similar for undoped samples $\left(7.2 \times 10^{-2} \mathrm{~S} / \mathrm{cm}\right)$ showing that $\mathrm{Zn}$ and $\mathrm{Co}$ has a positive effect on densification without compromising the electrical conductivity.
\end{abstract}

Keywords: gadolinium-doped ceria, cobalt addition, zinc addition, XPS, SOFC

\section{Introduction}

Solid oxide fuel cell (SOFC) has attracted considerable interest in the last few decades as a promising clean and efficient energy conversion device ${ }^{1-3}$. Classical designs employ yttria-stabilized zirconia (YSZ) as electrolyte, but it exhibits adequate ionic conductivity only at high temperatures $\left(900-1000^{\circ} \mathrm{C}\right)$. Such high temperatures limit the viability of fuel cells due to long-term stability and require expensive materials for sealing, insulation, and interconnects. Efforts to find new electrolyte materials with high electrical conductivity at lower SOFC operation temperatures have identified ceria based electrolytes as a substitute for $\mathrm{YSZ}^{2,3}$, and gadolinium-doped ceria (GDC) has shown to be amongst the most promising electrolytes ${ }^{4}$.

Ceria based electrolytes have been investigated over the past 20 years due to their high conductivity which makes them good candidates to be used at intermediate temperature $\left(500-700^{\circ} \mathrm{C}\right)^{3,5}$. A major difficulty in using ceria as electrolyte is related to the reduction of $\mathrm{Ce}^{+4}$ to $\mathrm{Ce}^{+3}$, which is significant at low oxygen partial pressure $\left(\mathrm{p}\left(\mathrm{O}_{2}\right)<10^{-15} \mathrm{~atm}\right)$ and high temperature $\left(\mathrm{T}>800^{\circ} \mathrm{C}\right)^{6}$. Another drawback regarding ceria solid solutions is their poor sinterability, which requires high temperatures $\left(1400-1600{ }^{\circ} \mathrm{C}\right)$ to achieve high densification $(>95 \%)^{5}$.

Adequate methods have been developed to prepare dense ceria-based electrolytes at lower temperature, allowing for

* e-mail: luciaavb@gmail.com the electrolyte-electrode co-sintering, which simplifies the fabrication process and reduces the cost. Three methods are the most used to achieve high densifications at low temperatures. One is based on decreasing the particle size of the powder to the nanoscale, hence increasing the driving force, i.e. specific surface area, for densification, thus the sintering temperatures are drastically reduced ${ }^{7}$. Conventional powders sinter at $0.5-0.8 \mathrm{~T}_{\mathrm{m}}$ (melting temperature), while nanopowders conveniently deagglomerated might sinter at temperatures as low as $0.2-0.3 \mathrm{~T}_{\mathrm{m}}$ for similar high density ${ }^{8}$. A second method consists on the use of sintering aids to promote densification through liquid phase sintering or assisted ionic flow along the grain boundaries ${ }^{9}$. Small amounts of sintering aids, e.g. $\mathrm{CoO}, \mathrm{MnO}, \mathrm{Fe}_{2} \mathrm{O}_{3}$, and $\mathrm{CuO}$ are very effective with respect to densification, but some of them exhibit a detrimental influence on grain boundary conductivity ${ }^{9-12}$. Recent work has showed the effectiveness of $\mathrm{ZnO}$ as sintering aid for yttrium-doped ceria (YDC), samarium-doped ceria (SDC), and $\mathrm{GDC}^{13}$. A third method involves the optimization of the sintering temperature profile, using the so-called two-step sintering route, with a peak temperature to activate the densification diffusion process, followed by a lower temperature dwell to proceed with densification with minimum grain growth ${ }^{14}$.

While the role of Co additions has been widely studied in recent years, the effect of $\mathrm{Zn}$ as sintering aid is less known. Furthermore, there is no systematic comparison between additives following a similar processing route, and starting from identical powders. In this work, the concomitant use 
of nanopowders and cobalt and zinc as sintering aids has been investigated together with the two-step sintering route. The sinterability, microstructure, and electrical conductivity of $\mathrm{Co}$ - and $\mathrm{Zn}$-doped $\mathrm{Ce}_{0.8} \mathrm{Gd}_{0.2} \mathrm{O}_{1.9}$ samples were evaluated against the performance of undoped powders.

\section{Experimental}

$\mathrm{Ce}_{0.8} \mathrm{Gd}_{0.2} \mathrm{O}_{1.9}$ (CGd), 2 mol\% CoO-doped $\mathrm{Ce}_{0.8} \mathrm{Gd}_{0.2} \mathrm{O}_{1.9}$ (CGd-Co), and 0.2, 0.4 and $1 \mathrm{~mol} \% \mathrm{ZnO}$-doped $\mathrm{Ce}_{0.8} \mathrm{Gd}_{0.2} \mathrm{O}_{1.9}$ (CGd-0.2Zn, CGd-0.4Zn and CGd-1Zn, respectively), were studied in this work. The starting materials were CGd (Fuel Cell Materials) with $32.6 \mathrm{~m}^{2} / \mathrm{g}$ specific surface area, $\mathrm{Co}\left(\mathrm{NO}_{3}\right)_{2} \cdot 6 \mathrm{H}_{2} \mathrm{O}$ (Synth, 98\% purity), and $\mathrm{Zn}\left(\mathrm{NO}_{3}\right)_{2} \cdot 6 \mathrm{H}_{2} \mathrm{O}$ (Synth, 99.98\% purity). Appropriate amounts of these powders were mixed in isopropanol containing $1 \mathrm{wt} \%$ of poly-vinylbutyral (B-98, Solutia), in a vibratory mill with zirconia milling media. Before uniaxial pressing at $40 \mathrm{MPa}$, the suspensions were dried in air and granulated through a nylon sieve. The resulting pellets were isostatically pressed at $200 \mathrm{MPa}$ and afterwards sintered following a two-step profile.

Information on early stages of sintering was obtained by dilatometry (Linseis L75, vertical) under a constant heating rate of $5^{\circ} \mathrm{C} / \mathrm{min}$. The peak sintering temperatures were thus adjusted to 1200 and $1000^{\circ} \mathrm{C}$, while the dwell temperatures were 1000 and $900{ }^{\circ} \mathrm{C}$ for 5 and $10 \mathrm{~h}$, respectively, at fixed heating/cooling rates of $5^{\circ} \mathrm{C} / \mathrm{min}$. A short designation of the sintering conditions hereby adopted includes sequentially the peak and dwell temperatures, the latter followed by the dwell time (e.g., $1200-1000{ }^{\circ} \mathrm{C} / 10 \mathrm{~h}$ ).

The structure of the sintered samples was characterized by a Siemens D5000 X-ray diffractometer using Cu $\mathrm{K} \alpha$ source. Samples densities were measured using the Archimedes method. The microstructure of the polished and thermally etched surfaces was analyzed by scanning electron microscopy (SEM, Philips XL 30 FEG). The average grain size was measured by the mean lineal intercept method. Sintered samples were also analyzed by transmission electron microscopy (TEM, Hitachi H-9000).

X-ray photoelectron spectroscopy (XPS) results were obtained by a VSW HA-100 spherical analyzer using nonmonochromated Al $\mathrm{K} \alpha$ radiation $(\mathrm{h} v=1486.6 \mathrm{eV})$. The high resolution spectra were acquired using constant analyzer pass energy of $44 \mathrm{eV}$. The pressure inside the analysis chamber was kept bellow than $2 \times 10^{-8}$ mbar. The powdered samples were pressed into pellets and fixed to a stainless steel sample holder with double-faced conducting tape and analyzed without further preparation. Curve fitting was performed using Gaussian line shapes, and a Shirley background was subtracted from the data.

The electrical conductivity of the specimens was measured in air over the temperature range $200-800{ }^{\circ} \mathrm{C}$ using (two-probe) impedance spectroscopy (HP 4192 A) over the frequency range $5 \mathrm{~Hz}$ to $13 \mathrm{MHz}$, with a test signal amplitude of $500 \mathrm{mV}$. Platinum paste electrodes were applied on both sides of the pellets.

\section{Results and Discussion}

\subsection{Sintering Characterization}

In order to analyze the effects of cobalt and zinc additions on the ceria-based solid solutions sintering process, a dilatometric analysis was performed (Figure 1). Pure CGd stars to shrink at approximately $800{ }^{\circ} \mathrm{C}$, while $\mathrm{CGd}-0.4 \mathrm{Zn}$ and CGd-Co show early signs of densification already at 400 ${ }^{\circ} \mathrm{C}$. Once densification starts it proceeds at a much higher rate in the $\mathrm{Zn}$ and Co doped samples than in pure CGd.

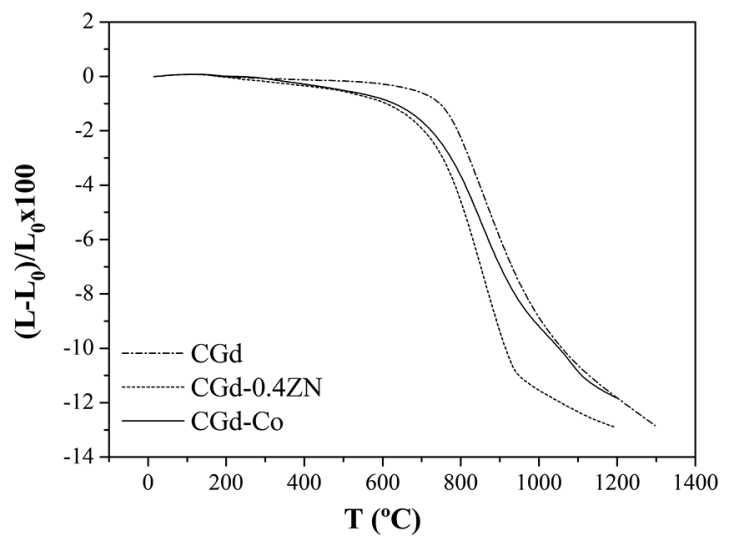

Figure 1: Shrinkage profiles obtained for undoped, zinc, and cobalt-doped samples.

The densification curve (Figure 2) was calculated from the dilatometry data using equation $1^{15}$ :

$$
\% \rho_{t h}=100\left(\frac{L_{f}}{L_{t}}\right)^{3} \frac{\rho_{f}}{\rho_{t}}
$$

where $\% \rho_{t h}$ is the percentage of theoretical density, $L_{f}$ is the final sample length, $L_{t}$ is the time length dependent and is equal to $L_{0}-\Delta L_{0}\left(L_{0}\right.$ is the initial sample length and $\Delta L_{0}$ is the sample displacement during time, $t$ ), $\rho_{t}$ is the theoretical sample density and $\rho_{f}$ is the final sample density.

For $\mathrm{Zn}$ and Co-doped samples a considerable improvement of the sintering kinetics is observed (Figure 2). It can also be seen that the densification is completed within a narrow temperature interval for CGd-Co, indicating a faster densification and the temperature to achieve $90 \%$ of densification is $\sim 900{ }^{\circ} \mathrm{C}$. However, for CGd and CGd- $0.4 \mathrm{Zn}$ samples, the temperature to attain the same densification is 1300 and $1220^{\circ} \mathrm{C}$, respectively.

$\mathrm{Zn}$ and Co-additions (up to $1 \mathrm{~mol} \%$ ) have a major impact on densification, as shown by the relative densities of the 


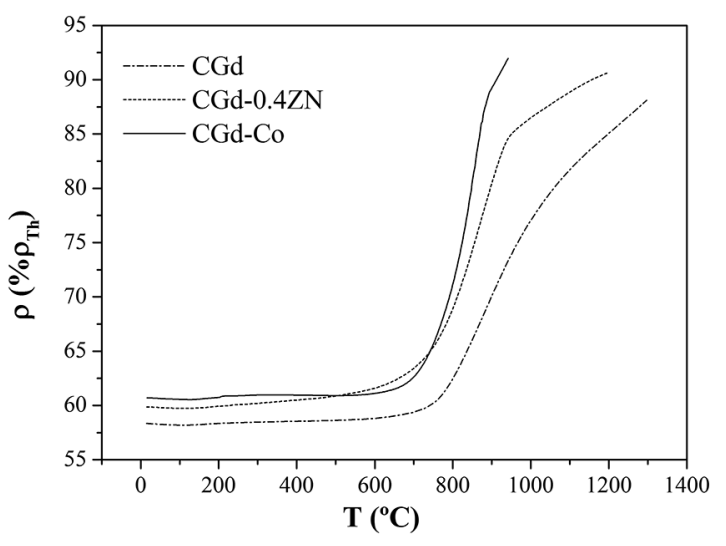

Figure 2: Percentage of theoretical density $\left(\% \rho_{t h}\right)$ as function of temperature for CGd, CGd-0.4Zn and CGd-Co.

sintered samples in Table 1. Co or $\mathrm{Zn}$ additions favored the densification, with peak sintering temperatures as low as $1000{ }^{\circ} \mathrm{C}$ achieving densifications higher than $93 \%$. These results agree with previously reported ones ${ }^{9,11-13}$.

\subsection{Structural and Microstructural Characterization}

Figure 3 presents the XRD diffractograms of the sintered samples. The diffraction peaks are indexed to the expected cubic fluorite structure, with no evidence for the presence of secondary phases. The additions of $\mathrm{Co}$ and $\mathrm{Zn}$ caused minimal changes in the lattice parameter, with a slight increase for the Zn-doped samples. Other authors did not detected either a secondary phase for the additions of 2 at. $\%$ of cobalt ${ }^{12}$ and 1 at. $\% \mathrm{Zn}^{13}$ to CGd. If secondary phases are formed, they are below the XRD detection limit.

Figure 4 displays SEM micrographs of the sintered samples. (a) CGd-1200-1000 ${ }^{\circ} \mathrm{C} / 10 \mathrm{~h}$ fracture sintered sample, (b) CGd-0.4Zn-1000-900 ${ }^{\circ} \mathrm{C} / 5 \mathrm{~h}$ fracture sintered sample, (c) and (d) polished and thermally etched surfaces of CGd-0.4Zn and CGd-Co samples, respectively, sintered at $1200-1000{ }^{\circ} \mathrm{C} / 10 \mathrm{~h}$. It can be observed the beneficial effect of the sintering aids. The Co addition caused the grains grow more steeply than the $\mathrm{Zn}$ additions (Table 1).

Figure 5 displays dark field TEM micrographs of (a) CGd and (b) CGd-1Zn samples sintered at $1200-1000{ }^{\circ} \mathrm{C} / 10 \mathrm{~h}$. The micrographs show a homogeneous microstructure for the undoped and $\mathrm{Zn}$-doped samples. An energy dispersive spectroscopy (EDS) analysis detected only Ce (79.2 at.\%) and $\mathrm{Gd}(20.8$ at.\%). It was not possible to detect the presence of $\mathrm{Zn}$ due to the low amount used, probably below the detection limit.

\subsection{XPS Analysis}

The chemical states of the constituent ions were analyzed by XPS. The Ce $3 \mathrm{~d}$ spectrum is characterized by a complex line shape that reflects the final state occupation of the $\mathrm{Ce}$ $4 \mathrm{f}$ level. $\mathrm{CeO}_{2}$ presents three pairs of spin-orbit doubles, while $\mathrm{Ce}_{2} \mathrm{O}_{3}$ presents only two pairs ${ }^{16,17}$. The spin-orbit doublets are commonly denoted $v$ and $u$ and represent the $3 \mathrm{~d}_{5 / 2}$ and $3 \mathrm{~d}_{3 / 2}$ states, respectively. The $v$ and $v$ " peaks are attributed to a mixture of $3 d^{9} 4 f^{2}\left(\mathrm{O} 2 p^{4}\right)$ and $3 d^{9} 4 f^{1}\left(\mathrm{O} 2 p^{5}\right)$

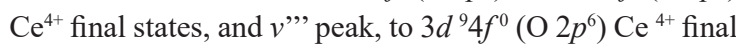
state $^{17}$. The series of $u$ structures from the $3 \mathrm{~d}_{3 / 2}$ level can be explained in the same way. The $v^{0}$ and $v^{\prime}$ peaks correspond to the $3 d^{9} 4 f^{2}\left(\mathrm{O} 2^{5}\right)$ and $3 d^{9} 4 f^{1}\left(\mathrm{O} 2 p^{6}\right) \mathrm{Ce}^{3+}$ final states, respectively ${ }^{18}$. The peak at approximately $916.5 \mathrm{eV}$ is used to identify the existence of $\mathrm{Ce}^{4+}$, since it is assigned to $4 \mathrm{f}^{0}$ transitions, which do not occur for $\mathrm{Ce}^{3+16,17}$.

Figure 6 displays the Ce $3 \mathrm{~d}$ XP-spectra for the following samples: (a) CGd, (b) CGd-0.2Zn, (c) CGd-0.4Zn, (d) CGd-1Zn, and (e) CGd-Co. The addition of $0.2 \mathrm{~mol} \%$ Zn (Figure 6(b)) caused a small change in the spectrum, noticeable by the appearance of a small contribution at lower binding energy, related to the $v^{0}$ peak. The additions of higher amounts of $\mathrm{Zn}$ provoked an enhancement of this $v^{0}$ peak (Figures 6(c) and 6(d)). The addition of Co caused even a more noticeable change (Figure 6(e)). These changes in the $\mathrm{Ce} 3 \mathrm{~d}$ spectra are attributed to a partial reduction of $\mathrm{Ce}^{4+}$ to $\mathrm{Ce}^{3+}$. It seems that the $v^{0}$ peak intensity increases with the increase in the amount of $\mathrm{Zn}$. It should be mentioned that a substantial degree of reduction of $\mathrm{Ce}^{4+}$ to $\mathrm{Ce}^{3+}$ during XPS measurements can occur when the measurement time is extended to several hours ${ }^{19}$.

From XPS analyzes, it was possible to identify the chemical changes in cerium ion valence state that occur in CGd samples. The major problem in using doped ceria as electrolyte is the relatively easy reduction of $\mathrm{Ce}^{+4}$ to $\mathrm{Ce}^{+3}$ at low oxygen partial pressure and high temperature (typical SOFC anode conditions), which creates an undesirable electronic conduction and leads to a chemical expansion of the lattice parameters. The electronic conduction decreases the fuel conversion efficiency due to partial internal short circuit and the chemical expansion influences the mechanical

Table 1: Green, final relative density and average grain size of samples sintered by a two-step method.

\begin{tabular}{lccc}
\hline Composition - Peak-Dwell temperature/Time & Green density (\%) & Sintered density (\%) & Average grain size (nm) \\
\hline CGd $-1200-1000{ }^{\circ} \mathrm{C} / 10 \mathrm{~h}$ & 57.5 & 91.8 & $201 \pm 28$ \\
CGd- $0.4 \mathrm{Zn}-1000-900^{\circ} \mathrm{C} / 5 \mathrm{~h}$ & 62.1 & 93.3 & $137 \pm 13$ \\
$\mathrm{CGd}-0.4 \mathrm{Zn}-1200-1000{ }^{\circ} \mathrm{C} / 10 \mathrm{~h}$ & 62.1 & 96.0 & $230 \pm 12$ \\
$\mathrm{CGd}-\mathrm{Co}-1200-1000{ }^{\circ} \mathrm{C} / 10 \mathrm{~h}$ & 61.1 & 99.6 & $450 \pm 23$ \\
\hline
\end{tabular}




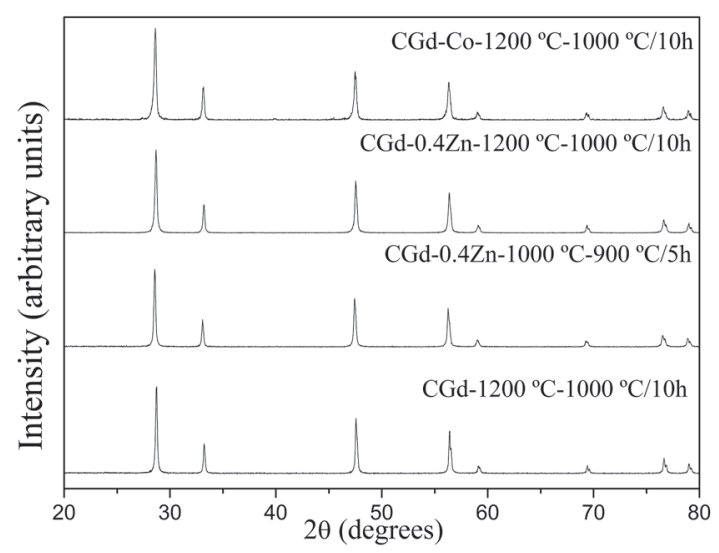

Figure 3: XRD diffractograms of the sintered samples.
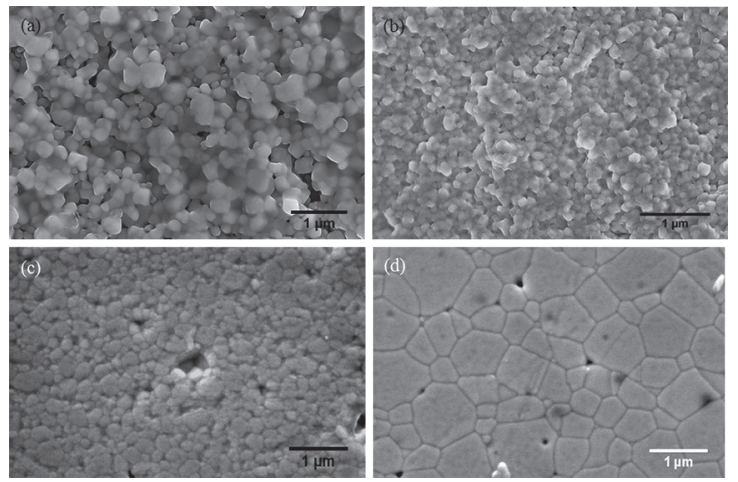

Figure 4: SEM micrographs of the sintered samples: (a) CGd-1200$1000{ }^{\circ} \mathrm{C} / 10 \mathrm{~h}$ fracture sintered sample, (b) CGd-0.4Zn-1000-900 ${ }^{\circ} \mathrm{C} / 5 \mathrm{~h}$ fracture sintered sample, (c) and (d) polished and thermally etched surfaces of CGd-0.4Zn and CGd-Co samples, respectively, sintered at $1200-1000{ }^{\circ} \mathrm{C} / 10 \mathrm{~h}$.
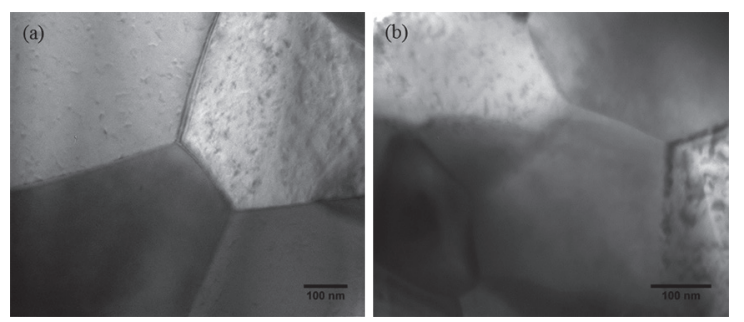

Figure 5: Dark field TEM micrographs of (a) CGd and (b) CGd$1 \mathrm{Zn}$ samples sintered at $1200-1000^{\circ} \mathrm{C} / 10 \mathrm{~h}$.

integrity of cells $\mathrm{s}^{6}$. The addition of either $\mathrm{Zn}$ or Co caused a small change in the Ce $3 \mathrm{~d}$ spectra, indicating only a partial reduction of cerium, however, the impact of these additions on the n-type conductivity of CGd is minimal.

The Gd $4 \mathrm{~d}$ spectra (not shown here) appear as a broad structure containing two main contributions, $\mathrm{Gd}_{4 \mathrm{~d}_{5 / 2}}$ and $\mathrm{Gd} 4 \mathrm{~d}_{3 / 2}{ }^{20}$, and are very similar to the one obtained by Cheng et al. ${ }^{21}$ for a $\mathrm{Gd}_{2} \mathrm{O}_{3}$ film deposited on silicon. For all analyzed samples, the binding energy of the $\mathrm{Gd}^{4} \mathrm{~d}_{5 / 2}$ peak is around $140.7 \mathrm{eV}$, which is very close to the value (140.9 $\mathrm{eV}$ ) reported by Kossoy et al..$^{22}$ for $\mathrm{Ce}_{0.8} \mathrm{Gd}_{0.2} \mathrm{O}_{1.9}$ thin films.

\subsection{Electrical Conductivity}

Figure 7 shows the impedance spectra, measured at 250 ${ }^{\circ} \mathrm{C}$, of the samples sintered at $1200-1000{ }^{\circ} \mathrm{C} / 10 \mathrm{~h}$, corrected for their thickness and electrode area. Impedance spectra of samples containing sintering aids showed the usual characteristics commonly reported for polycrystalline solid electrolytes, with one high frequency arc (ascribed to the bulk contribution), one intermediate frequency arc (related to the grain boundary contribution), besides the lower frequency electrode response often resembling a tail. However, with increasing temperature, the relaxation frequency of the high frequency arc exceeds the upper limit of the equipment, and this arc disappears gradually. The intermediate frequency semicircle displays the same tendency so that at temperatures higher than $500^{\circ} \mathrm{C}$, the impedance spectra showed only the electrode response.

The impedance spectra of samples free of sintering aid sometimes show a higher degree of overlapping of the semicircles for grain and grain boundary (e.g., see Figure 7) than in the spectra of the doped samples. Instead of well resolved contributions, the result is a depressed impedance arc which can be deconvoluted into specific contributions with the typical relaxation frequencies of grain and grain boundary.

The impedance spectra were fitted by means of the ZView program. Different elementary equivalent circuits arranged in series, each consisting of one resistance $(\mathrm{R})$ and one constant phase element (CPE) in parallel, were adopted as base model. The CPE elements are often used instead of simple capacitors when the impedance data deviates from perfect semicircles, appearing instead as depressed $\operatorname{arcs}^{23}$. Each specific contribution (grain, grain boundary, and electrode) was ascribed to one of these elementary circuits, except in the higher temperature range where the arcs related to ionic transport were not well defined. In such cases only the cell total resistance (bulk+grain boundary) was considered.

The data shown in Figure 7 suggest that the sintering aids influenced slightly the low temperature performance, but there was no clear trend. Anyhow, even small differences at low temperature quickly vanished with increasing temperature, as it is shown in the following discussion. The bulk $\left(\sigma_{\mathrm{b}}\right)$ and total $\left(\sigma_{t}\right)$ electrical conductivities were calculated from the corresponding (bulk and total=bulk+grain boundary) $\mathrm{R}$ values taking into account the sample geometry. The grain boundary conductivity was calculated assuming estimates for the grain boundary thickness and grain size, to calculate the microscopic grain boundary conductivity $\left(\sigma_{g b}^{\text {mico }}\right)$. The $\sigma_{g b}^{\text {micro }}$ can be calculated as usual ${ }^{24}$.

Figure 8 depicts Arrhenius plots of the bulk and microscopic grain boundary electrical conductivities measured in air for specimens sintered $1200-1000{ }^{\circ} \mathrm{C} / 10 \mathrm{~h}$. Both bulk and grain boundary conductivities of $\mathrm{Zn}$ and Co-doped samples were a little higher than undoped samples, which may be explained by preferential segregation of $\mathrm{Zn}$ and $\mathrm{Co}$ at grain boundary 

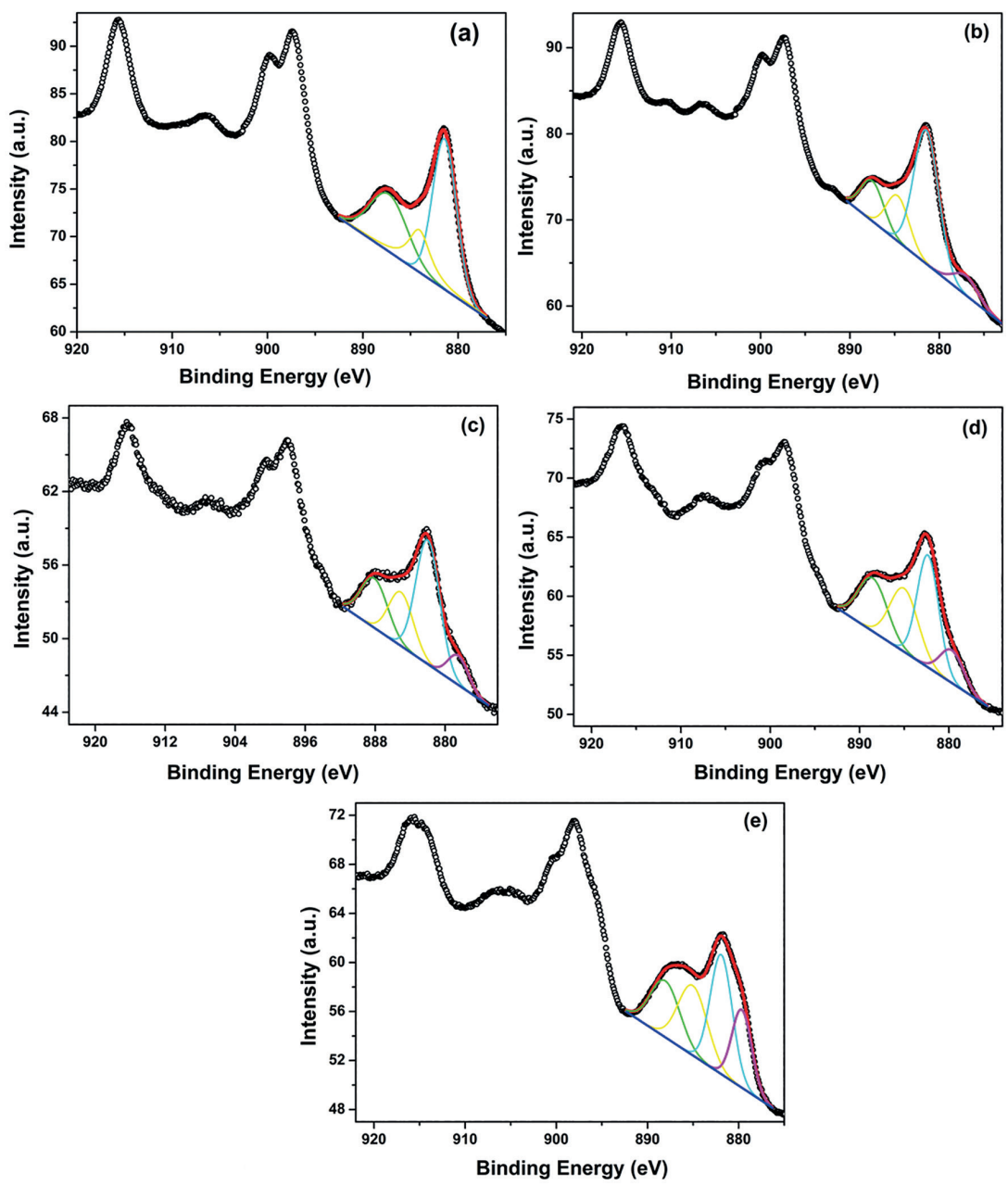

Figure 6: Ce 3d XPS-spectra for the following samples: (a) CGd, (b) CGd-0.2Zn, (c) CGd-0.4Zn, (d) CGd-1Zn, and (e) CGd-Co.

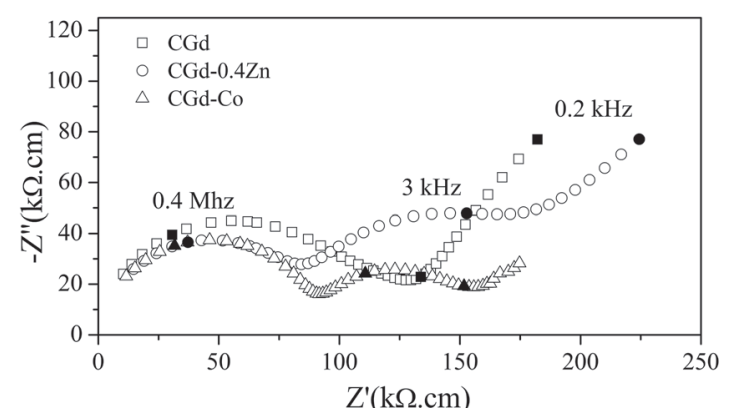

Figure 7: Impedance spectra, measured at $250^{\circ} \mathrm{C}$, of the samples sintered at $1200-1000^{\circ} \mathrm{C} / 10 \mathrm{~h}$.

rather than Gd. This behavior affects both bulk and grain boundary electrical properties. In the bulk, the conductivity is higher probably due to the augment of oxygen vacancies with the formation of solid solution among $\mathrm{Gd}_{2} \mathrm{O}_{3}$ and $\mathrm{CeO}_{2}$. The grain boundary is less resistive with sintering aids due to space charge effects, since dopant segregation at grain boundaries might damage the ionic conductivity. The behavior observed here can be attributed to the influence of sintering aid on the grain boundary thickness $\left(\delta_{\mathrm{gb}}\right)$, as it has been exhaustively discussed for doped-ceria and yttriastabilized zirconia ${ }^{23}$. The $\delta_{\mathrm{gb}}$ values for Co and $\mathrm{Zn}$-doped and nondoped samples analyzed at $300^{\circ} \mathrm{C}$ in air were calculated using equation 2 and are shown in Table 2 :

$$
\delta_{g b}=\frac{\varepsilon_{\mathrm{gb}}}{\varepsilon_{\mathrm{g}}} \frac{\mathrm{C}_{\mathrm{g}}}{\mathrm{C}_{\mathrm{gb}}} d_{\mathrm{g}} \sim \frac{\mathrm{C}_{\mathrm{g}}}{\mathrm{C}_{\mathrm{gb}}} d_{\mathrm{g}}
$$

Where $\varepsilon_{\mathrm{gb}}$ and $\varepsilon_{\mathrm{g}}$ are the grain boundary and grain permittivity that were considered equal, $\mathrm{C}_{\mathrm{g}}$ and $\mathrm{C}_{\mathrm{gb}}$ are, respectively, the capacitances for grain and grain boundary, and is the average grain size. The terms $\varepsilon_{\mathrm{gb}}$ and $\varepsilon_{\mathrm{g}}$ can be approximately equal since the dielectric constant of $\mathrm{CeO}_{2}$ is insensitive to the concentration ${ }^{23}$.

The $\delta_{\mathrm{gb}}$ is lower for Co addition than $\mathrm{Zn}$ addition, independently of shape, probably indicating that $\mathrm{Co}$ and $\mathrm{Zn}$ 

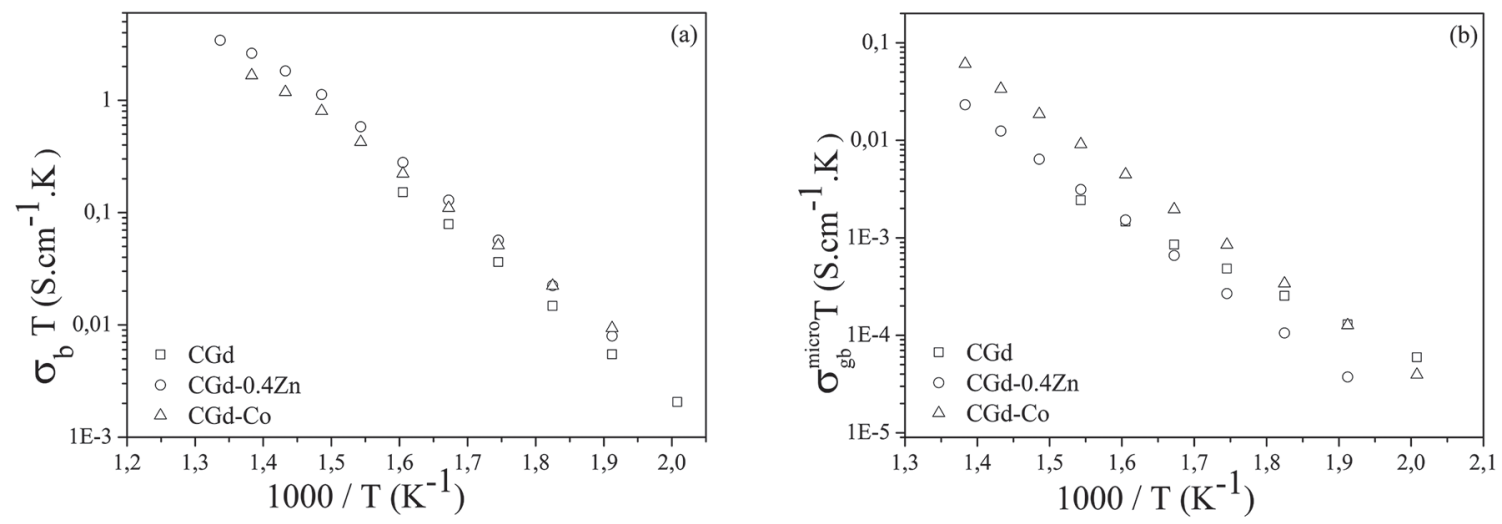

Figure 8: Arrhenius plots of (a) bulk and (b) microscopy grain boundary electrical conductivities measured in air of the samples sintered at $1200-1000^{\circ} \mathrm{C} / 10 \mathrm{~h}$.

Table 2: Activation energies for the bulk $\left(\mathrm{E}_{\mathrm{ab}}\right)$ and microscopic grain boundary $\left(\mathrm{E}_{\mathrm{agb}}\right)$ conductivities, grain boundary thickness $\left(\delta_{\mathrm{gb}}\right)$ at $300{ }^{\circ} \mathrm{C}$, measured in air, of samples sintered at $1200-1000{ }^{\circ} \mathrm{C} / 10 \mathrm{~h}$.

\begin{tabular}{lcccc}
\hline Composition & \multicolumn{2}{c}{$\mathrm{E}_{\mathrm{ab}}(\mathrm{eV})$} & $\mathrm{E}_{\mathrm{agb}}(\mathrm{eV})$ & $\delta_{\mathrm{gb}}$ at $300{ }^{\circ} \mathrm{C}(\mathrm{nm})$ \\
\hline $\mathrm{CGd}$ & 0.93 & $\mathrm{~T}>400{ }^{\circ} \mathrm{C}$ & 0.70 & 2.79 \\
CGd-0.4Zn & 1.00 & 0.58 & 1.05 & 2.17 \\
CGd-Co & 0.91 & 0.67 & 1.01 & 1.73 \\
\hline
\end{tabular}

segregate more at the grain boundary than $\mathrm{Gd}$, and this may be correlated to a preferential segregation of the sintering aids rather than the addition of rare earth, and the enhancement of the conductivity may due to change in the space charge layer structure. It is noteworthy that the relative low $\mathrm{Co}-\mathrm{O}$ bond dissociation and low solubility of cobalt in ceria corroborate with the higher segregation of Co at the grain boundary ${ }^{12}$.

Figure 9 presents the Arrhenius plots of total electrical conductivity $\left(\sigma_{t}\right)$ measured in air of the samples sintered at $1200-1000{ }^{\circ} \mathrm{C} / 10 \mathrm{~h}$. The differences are relatively small, suggesting that the additions of $\mathrm{Co}$ and $\mathrm{Zn}$ have little influence on the electrical properties of ceria-based solid solutions. At temperatures higher than $500{ }^{\circ} \mathrm{C}\left(1000 / \mathrm{T} \approx 1.3 \mathrm{~K}^{-1}\right)$, all lines almost overlap.

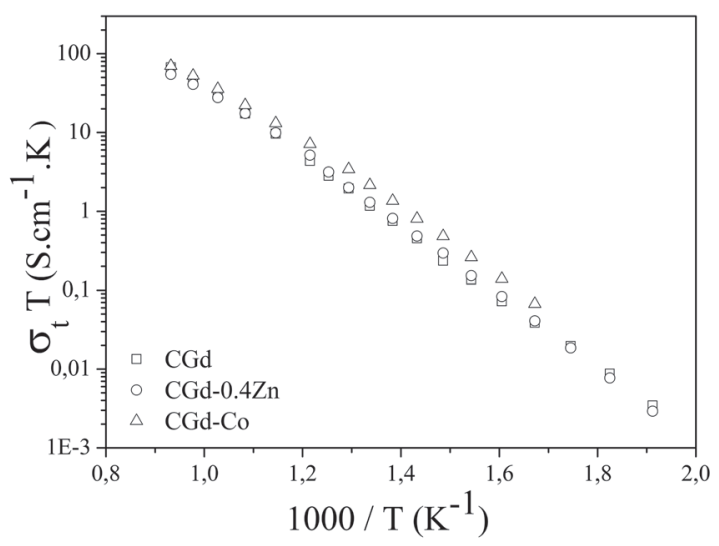

Figure 9: Arrhenius plots of total electrical conductivity measured in air of the samples sintered at $1200-1000{ }^{\circ} \mathrm{C} / 10 \mathrm{~h}$.
The sets of total conductivity data at $800^{\circ} \mathrm{C}$ and activation energies are listed in Table 3. The overall conductivity results, including low temperature activation energies in the range 0.8 to $1.0 \mathrm{eV}$, match the corresponding values for $\mathrm{Zn}$ - and $\mathrm{Co}$-free samples. This result suggests that $\mathrm{Zn}$ additions have a positive role on the sintering without the formation of ion-blocking grain boundaries, thus resembling Co-doped CGd rather than other ceria-based ceramic materials doped with different sintering aids such as $\mathrm{Mn}$ and $\mathrm{Fe}^{9}$. The results observed in this work agree well with results reported by Pérez-Coll et al. ${ }^{12}$ and Ge et al. ${ }^{13}$.

\section{Conclusions}

Two-step sintering combined with zinc additions, starting from a nanopowder, successfully produced high density $\mathrm{Ce}_{0.8} \mathrm{Gd}_{0.2} \mathrm{O}_{1.9}$ samples ( $>93 \%$ ) at low peak/dwell temperature $\left(\mathrm{T}_{\text {peak }}=1000^{\circ} \mathrm{C}\right.$ and $\left.\mathrm{T}_{\mathrm{dwell}}=900^{\circ} \mathrm{C} / 5 \mathrm{~h}\right)$ without the presence of secondary phases. However, Co additions increased the grain size, while zinc had only a marginal effect on grain growth. $\mathrm{Zn}$ and Co additions have a considerable effect on sintering kinetics by improving the densification in comparison with pure CGd samples.

In particular, the chemical states of the constituents were analyzed by XPS and the addition of either $\mathrm{Zn}$ or Co caused a change in the Ce $3 \mathrm{~d}$ spectra, indicating a partial reduction of $\mathrm{Ce}^{4+}$. The total conductivity of ceria electrolytes with additives was similar to undoped samples. $\mathrm{Zn}$ - and Co-additions had a positive role on sintering without the formation of ion-blocking grain boundaries, since the total conductivities were similar to that of undoped samples. 
Table 3: Total conductivity $\left(\sigma_{t}\right)$ at $800^{\circ} \mathrm{C}$ and activation energies for total conductivity $\left(E_{a t}\right)$ in air of sample sintered at $1200-1000{ }^{\circ} \mathrm{C} / 10 \mathrm{~h}$.

\begin{tabular}{lccc}
\hline Composition & $\mathrm{T}<600{ }^{\circ} \mathrm{C}$ & $\mathrm{E}_{\mathrm{at}}(\mathrm{eV})$ & $\mathrm{T}>600{ }^{\circ} \mathrm{C}$ \\
\hline CGd & 0.88 & 0.77 & $\sigma_{\mathrm{t}}$ at $800{ }^{\circ} \mathrm{C}(\mathrm{S} / \mathrm{cm}) \times 10^{-2}$ \\
CGd-0.4Zn & 0.91 & 0.65 & 6.2 \\
CGd-Co & 0.90 & 0.66 & 7.5 \\
\hline
\end{tabular}

\section{Acknowledgements}

Financial supports from CAPES and CNPq are greatly appreciated. We would like to thank Rita C. G. Vinhas (State University of Campinas, Campinas Campus, Brazil), for helping with the XPS measurements.

\section{References}

1. Ormerod RM. Solid oxide fuel cells. Chemical Society Reviews. 2003;32(1):17-28.

2. Zhu B. Solid oxide fuel cell (SOFC) technical challenges and solutions from nano-aspects. International Journal of Energy Research. 2009;33(13):1126-1137.

3. Jacobson AJ. Materials for Solid Oxide Fuel Cells. Chemistry of Materials. 2010;22(3):660-674.

4. Steele BCH. Appraisal of $\mathrm{Ce}_{1-y} \mathrm{Gd}_{y} \mathrm{O}_{2-y / 2}$ electrolytes for ITSOFC operation at $500^{\circ}$ C. Solid State Ionics. 2000;129(14):95-110.

5. Prasad DH, Lee JH, Lee HW, Kim BK, Park JS. Correlation between the powder properties and sintering behaviors of nano-crystalline gadolinium-doped ceria. Journal of Ceramic Processing Research. 2010;11(5):523-526.

6. Figueiredo FML, Marques FMB. Electrolytes for solid oxide fuel cells. Wiley Interdisciplinary Reviews: Energy and Environment. 2013;2(1):52-72.

7. Singh V, Babu S, Karakoti AS, Agarwal A, Seal S. Effect of submicron grains on ionic conductivity of nanocrystalline doped ceria. Journal of Nanoscience and Nanotechnology. 2010;10(10):6495-6503.

8. Groza JR. Nanosintering. Nanostructured Materials. 1999;12(58):987-992.

9. Zhang X, Decès-Petit C, Yick S, Robertson M, Kesler O, Maric $\mathrm{R}$, et al. A study on sintering aids for $\mathrm{Sm}_{0.2} \mathrm{Ce}_{0.8} \mathrm{O}_{1.9}$ electrolyte. Journal of Power Sources. 2006;162(1):480-485.

10. Zhang TS, Ma J, Leng YJ, Chan SH, Hing P, Kilner JA. Effect of transition metal oxides on densification and electrical properties of Si-containing $\mathrm{Ce}_{0.8} \mathrm{Gd}_{0.2} \mathrm{O}_{2-\delta}$ ceramics. Solid State Ionics. 2004;168(1-2):187-195.

11. Gao L, Zhou M, Zheng Y, Gu H, Chen H, Guo L. Effect of zinc oxide on yttria doped ceria. Journal of Power Sources. 2010;195(10):3130-3134.
12. Pérez-Coll D, Marrero-López D, Núñez P, Piñol S, Frade JR. Grain boundary conductivity of $\mathrm{Ce}_{0.8} \mathrm{Ln}_{0.2} \mathrm{O}_{2-\delta}$ ceramics ( $\mathrm{Ln}=$ $\mathrm{Y}, \mathrm{La}, \mathrm{Gd}, \mathrm{Sm}$ ) with and without Co-doping. Electrochimica Acta. 2006;51(28):6463-6469.

13. Ge L, Li S, Zheng Y, Zhou M, Chen H, Guo L. Effect of zinc oxide doping on the grain boundary conductivity of $\mathrm{Ce}_{0.8} \mathrm{Ln}_{0.2} \mathrm{O}_{1.9}$ ceramics $(\mathrm{Ln}=\mathrm{Y}, \mathrm{Sm}, \mathrm{Gd})$. Journal of Power Sources. 2011;196(15):6131-6137.

14. Lapa CM, de Souza DPF, Figueiredo FML, Marques FMB. Twostep sintering ceria-based electrolytes. International Journal of Hydrogen Energy. 2010;35(7):2737-2741.

15. Wang J, Raj R. Estimate of the Activation Energies for Boundary Diffusion from Rate-Controlled Sintering of Pure Alumina, and Alumina Doped with Zirconia or Titania. Journal of the American Ceramic Society. 1990;73(5):1172-1175.

16. Mullins DR, Overbury SH, Huntley DR. Electron spectroscopy of single crystal and polycrystalline cerium oxide surfaces. Surface Science. 1998;409(2):307-319.

17. Larsson PO, Andersson A. Complete Oxidation of CO, Ethanol, and Ethyl Acetate over Copper Oxide Supported on Titania and Ceria Modified Titania. Journal of Catalysis. 1998;179(1):72-89.

18. Le Normand F, El Fallah J, Hilaire L, Légaré P, Kotani A, Parlebas JC. Photoemission on 3d core levels of Cerium: An experimental and theoretical investigation of the reduction of cerium dioxide. Solid State Communications. 1989;71(11):885-889.

19. Paparazzo E, Ingo GM, Zacchetti N. X-ray induced reduction effects at $\mathrm{CeO}_{2}$ surfaces: An x-ray photoelectron spectroscopy study. Journal of Vacuum Science \& Technology A. 1991;9(3):1416-1420.

20. Raiser D. Deville JP. Study of XPS photoemission of some gadolinium compounds. Journal of Electron Spectroscopy and Related Phenomena. 1991;57(1):91-97.

21. Cheng X, Xu D, Song Z, He D, Yu Y, Zhao Q, Shen D. Characterization of gadolinium oxide film by pulse laser deposition. Applied Surface Science. 2009;256(3):921-923.

22. Kossoy A, Cohen H, Bendikov T, Wachtel E, Lubomirsky I. Water adsorption at the surface of pure and Gd-doped ceria. Solid State Ionics. 2011;194(1):1-4.

23. Guo X, Waser R. Electrical properties of the grain boundaries of oxygen ion conductors: Acceptor-doped zirconia and ceria. Progress in Materials Science. 2006;51(2):151-210.

24. Tian C, Chan SW. Ionic conductivities, sintering temperatures and microstructures of bulk ceramic $\mathrm{CeO}_{2}$ doped with $\mathrm{Y}_{2} \mathrm{O}_{3}$. Solid State Ionics. 2000;134(1-2):89-102. 